be spoken of at all. Habit and taste take its place. When Professor Osborne says that dietary habits which satisfy these promptings of instinct are among the most difficult to change, whereas those that do not satisfy instinct are easily changed, he shows a better acquaintance with the dietary habits of the albino rat than with that of his fellow men. Dietary habits are habits, and I have yet to see any dietary habits easy to break, or any other habit that has existed in an individual or a race for a generation or a century. For nearly two years I worked in Newfoundland among a people who suffered from deficiency diseases and in all that time they did not learn to eat more than one new food.

The changes that have gradually taken place in our dietary over the last one hundred and fifty years are extraordinary. Professor Osborne refers to the lack of vitamines in some of our highly milled flours and warns against them. Our American dietary tastes are more and more running toward these refined foods. Think of the prepared breakfast foods of today that did not exist a generation ago. Think of the changes that have come over our national dietary in one hundred and fifty years. For example, sugar consumption has increased during that time from one-fourth of a pound a year, perhaps, to one-fourth of a pound a day. Patent white flour in 1914 had almost completely replaced the partly bolted flours of two generations ago.

When we speak of instinct as a guide to a national dietary, we should consider the nation and the food supply. The Chinese have lived for thousands of years upon a natural dietary. We have lived for hundreds of years upon an ever-changing one and one which is becoming increasingly an artificial one. It is true that the West Indian negroes choose a diet for themselves that is nearly ideal. In the West Indies rickets is almost unknown among the negroes. Transplant these same negroes to New York City and ninety-eight out of one hundred have rickets. Instinct does not help them in their artificial environment. But a large part of our population are transplanted. The working peo: ple, from necessity, choose, what they can afford to buy. The Italians choose a very low protein diet and are physically efficient. The bankers and millionaires choose a high protein diet and are physically effete. The millionaire has not nearly so safe an instinct as the pig.
He has meat or eggs three times a day and fat in excessive quantities. Italian families here get meat once a week, eggs never, cheese and milk only in small quantities, and they eat their bread without butter. It is pretty safe to say that the laborer does not overeat, but the travelling salesman always does.

National dietary. studies, unfortunately, do not extend over hundreds and thousands of years, as they should to be of real value to the scientist. The effect of high protein diets on one generation may be small, on one hundred generations very great. The relationship between degenerative diseases,-vascular sclerosis, nephritis, diabetes,-and diet is unknown. I am told that high blood pressure is unknown in Korea. We know that degenerative diseases are increasing in this country, and that they always increase as a people become physically indolent and epicurean. The Chinese coolie, than whom no being performs more physical work, is a "seed-eating oriental." Why do not the English thrive in India? Because they take their insular habits of eating with them, and do not modify their dietary habits to conform with the climate and environment.

In the discussion of the nutrition of man we must carefully distinguish between races living under natural conditions, guided by instinct, and peoples living under more or less modified or artificial conditions and following tradition and habit. We must also take into consideration natural foodstuffs obtained by pure races and artificial, condensed and prepared foods shipped to our very doors and obtainable in ever increasing quantities. Climate and temperament modify the diets of races and individuals. In our country we have extremes of both and races living under the most unnatural conditions, in which from necessity instinct can play little if any rôle in their choice of aliment. Must we not teach the new American his particular dietary needs, both as to what and how much to eat?

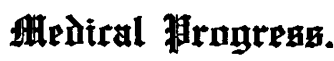

\section{PROGRESS OF OPHTHALMOLOGY.}

By Edmund W. Clap, M.D. Boston.

GLAUCOMA FROM ABSORPTION OF SENILE CATARACT.

GIFFORD thinks absorption of senile cataract not so rare as commonly supposed. He has 
seen ten cases of practically complete absorption of the cortex. In three of these useful sight was obtained. In six others glaucoma precluded this result. The author thinks that as everyone would develop a senile cataract if he lived long enough, so also everyone would obtain a spontaneous cure in time. But the frequency with which glaucoma occurs with the absorption of senile cataract has been noted by Mitvalsky and Reuss and Verrey. While these writers conclude that the glaucoma or some inflammatory complications cause the absorption, Gifford believes that it is the other way around. The spontaneous absorption causes an increase of tension either temporary and slight, or one that may lead to blindness. The author has now seven cases whose histories support his views. Where the cortex is absorbed or discharged into the anterior chamber a little at a time it is probable that a transient rise of tension occurs but does not attract attention on account of blindness and lack of pain. A larger quantity of cortex in the anterior chamber seems to excite a decided chemotaxis and when with irido-cyclitic symptoms any of this cortex is seen in the anterior chamber it is natural to take it for inflammatory exudate. Perhaps the evil results following couching may sometimes be due to glaucoma from absorption of cortex rather than to the bouncing about of the lens upon the ciliary processes. When the cortex is once absorbed there is danger of glaucoma from dislocation of the loose nucleus into the anterior chamber. Of course these views demand that a senile cataract should not be allowed to become too hypermature even if the other eye stil! has good vision.

EYE SYMPTOMS IN ACUTE INFECTIVE JAUNDICE.

Weil's disease was shown to be a pathological entity when, in 1914, a spirochaete allied morphologically to that of syphilis was described by several Japanese observers. They proposed to call it spirochaetosis ictero-hemorrhagica. It has appeared in epidemic forms in the armies of both sides. Weekers and Firket in Arch. d'Ophthat and Moret in Arch. Méd. Belges give detailed clinical descriptions and from the translation in the British Ophthalmic Journal the following summary of the ocu. lar signs is taken: Ocular hyperemia was noted in 46 out of 50 cases and appeared within the first few days. It varied from a slight redness to intense congestion with photophobia and lacrymation and redness of lids, but seldom any conjunctival secretion. It abates after sev. eral days but rarely disappears entirely until convalescence is established. Congestion of iris occurs and bilateral miosis and in some cases (9 out of 50) iritis and irido-cyclitis. Mild cases may escape notice but extensive synechiae may form. Atropine usually dilates the pupil fully and then exudate will be seen on the anterior capsule of the lens. These congestive signs are probably due to the local development of the parasite in the uveal tract. Two cases showed optic neuritis but no contraction of fields or central scotoma or diminution of visual acuity. One case had transient failure of sight with central scotoma without ophthalmoscopic changes. One case of acute herpes occurred involving cornea and conjunctiva as well as lids. Conjunctival jaundice was, of course, usual and of no especial significance. Three patients had subconjunctival hemorrhages. Moret believes the vaso-dilation is not of inflammatory origin but is due to disturb. ances of the angio-tonic function of the suprarenal bodies and the mild neuro-retinitis without functional disturbances he thinks is similar to that seen in other forms of anemia. Van Schevensteen reports retino-chorioiditis as a complication. Hertel (Arch. f. Ophthal.) from the German side finds the same ocular lesions and also reports one case of panophthalmitis. He made injection experiments on rabbits and marmots, finding spirochetes in the tissues of the eye always after intra-ocular injections in marmots and often after intra-peritoneal. Those in the conjunctiva might, he thinks, be a cause of new infections.

\section{ETIOLOGY OF ECZEMATOUS CONJUNCTIVITIS.}

Cridland has an excellent article on eczematous kerato-conjunctivitis in which recent views on the etiology are discussed. We quote him as follows: Much has been done to show the close relationship of this disease with tuberculosis. The phlyctenule is itself not a tuberculosis for no tubercle bacilli, alive or dead, have ever been found in one, in fact, no microorganisms are found though looked for by many observers. There is, however, much evidence that a tuberculous focus exists somewhere in the body in many cases. In many patients Nies and Paton found the opsonic index was lowered for tubercle and rose as the lesion improved, from which they concluded that the phlycten- 
ules were caused by attenuated or dead tubercle bacilli. Stephenson found that in one series of cases $50 \%$ showed clinical signs of medical or surgical tuberculosis, while $75 \%$ gave a family history of tubercle and in an. other series of 669 cases tubercle was present in nearly $40 \%$. Several other observers have found similar results. In 1912 Belenky Raskin tried von Pirquet's and Moro's tests on 100 consecutive cases of phlyctenular disease with positive von Pirquet in $90 \%$ and the Moro reaction in $85 \%$ and eight of the remainder had either tuberculosis or a family history of it. In two cases no such evidence was found. In view of the importance of diet in treatment we must conclude that gastro-intestinal disturbance is a more or less constant factor. Czerny's "exudative diathesis" is caused, he thinks, by an abnormality in the power of fat metabolism. Eczema appears and the child is a prey to infections. This diathesis is not more common in tuberculous families than in others, but is frequently found in nervous families. Overfeed. ing with milk and eggs or with carbohydrates brings out the symptoms, phlyctenules are common and the status lymphaticus is a most severe form of the condition. Lafon recognizes three groups: (1) Patients already tuberculous when the eye trouble begins. The cause of the eye lesion here is the toxins of the tubercle bacillus. (2) The eye mischief comes on after an infective malady. (3) Patients free from tubercle who appear to be healthy when the phlyctenule came. Morax says phlyctenular disease may be observed in children of the best health in whom all local tubercular infection may be eliminated and to whom we cannot apply the term scrofulous. Lafon thinks these cases, from injudicious feeding, get gastrointestinal toxins and that the organism in try ing to get rid of these provokes the formation of ocular phlyctenules. Of course exogenous causes may be considered, as local external treatment so often suffices and the phlyctenules often appear where external irritation is most likely to be effective. Axenfelt thinks the phlyctenule is the specific reaction of the scrofulous individual to all kinds of infection. Phlyctenules histologically typical may appear in the course of a conjunctivitis due to the pneumococcus, Weeks' bacillus or to the diplobacillus of Morax. The author concludes that we should recognize the existence of an hereditary diathesis which forms a bed rock upon which infection readily takes place. Faulty hygiene, bad and improper food opens the road still further to infection. The widespread tubercle bacilli is the one most successful and perhaps most suitable to such a soil, which then becomes scrofulous, but other infections can by their toxins give rise to phlyctenules. Hird also has a statistical article on tuberculosis as a cause of phlyctenular disease and its treatment with tuberculin, in which he is a firm believer.

\section{NITRO-PHENOL NEURITIS.}

Sollier and Jousset describe neuritic affections in French powder workers under slack hygienic conditions. In three cases extensive neuritis of spinal nerves was present as well as of optic nerves. The characteristics are those of toxic retrobulbar neuritis which may go on to atrophy. This neuritis seems due to nitrophenol bodies in the powders. Prophylactic administration of vasomotor constrictor drugs is suggested. The authors think they can exclude other causes as tobacco, alcohol and tabes and fix on dinitro benzol as the toxic agent.

\section{IRITIS IN DYSENTERY.}

Maxwell and Kiep report six cases of anterior uveitis developing in patients infected with B. dysenteriae (Shiga). In four of them arthritis occurred also. Other causes of iritis were excluded and the authors conclude: (1) A patient suffering from an infection by B. dysenteriae may develop anterior uveitis as a result of the infection, as pointed out by Morax. (2) The ocular affection may or may not be accompanied by articular manifestations. (3) The ocular symptoms would appear to occur most frequently about one month after the first signs of involvement of the bowel, but may occur as early as the twelfth day. (4) The articulo ocular syndrome corresponds exactly to that occurring in another affection of a mucous tract, viz., gonorrhea, as pointed out by Garrod. Maxwell has also reported six cases of metastatic conjunctivitis lasting five or six days in this dysentery.

\section{ASTIGMATISM}

Jackson has a statistical study of the changes taking place in astigmia. In 1,294 eyes out of 648 patients remeasured after periods of from five to seventeen years, $33 \%$ showed less than 
$.25 \mathrm{D}$ of change in the amount of astigmia pres- be known to others but which has not been deent and $67 \%$ showed at least that much change, scribed. The cases have occurred in young while $31 \%$ showed $.50 \mathrm{D}$ or more of change. subjects presenting some of the ordinary stigThese latter were more carefully worked out. mata of hereditary syphilis. Once both corneae Astigmia with the rule includes all cases in were affected at the same time and in other which the axis of the convex correcting cylinder was placed within $30^{\circ}$ of the vertical or the axis of the concave correcting cylinder was placed within $30^{\circ}$ of the horizontal. Astigmia against the rule includes those in which the axis of the convex cylinder was within $150^{\circ}$ and $30^{\circ}$, or the concave between $60^{\circ}$ and $120^{\circ}$. A majority of the cases showed change towards astigmia against the rule, $27 \%$ changed towards the rule and $10 \%$ remained or became oblique, viz., the axis of the correcting cylinder lay between $30^{\circ}$ and $60^{\circ}$ on the one hand, or between $120^{\circ}$ and $150^{\circ}$ on the other. In early life in. crease of astigmia with the rule predominates but there is a tendency for this to diminish or for astigmia against the rule to increase as life goes on. In cases showing a change of one diopter or more, ophthalmometric measurements showed that in one group the anterior surface of the cornea is an important location of the changes that have altered the astigmia, while in another group the supplementary astigmia is the cause of the change in the total amount. In general the tendency is for astigmia to increase with the rule by increase of the corneal astigmia, and to increase against the rule by inincrease of the supplementary astigmia. Astigmia, though due in some cases to a congenital tendency, develops during life. In some asymmetrical growth of lens is the most logical inference. Jackson concludes that astigmia is likely to change at any period of life and astigmia with the rule becomes astigmia gainst the rule often as the patient grows older. We should adopt a different nomenclature such as, Direct, with the meridian of greatest curvature approximately vertical; Inverse, with the meridian of greatest curvature approximately horizontal and oblique in the same sense as used above in this article. Astigmia is congenital chiefly in the sense that a tendency to asymmetrical refraction exists which works itself out at some stage in the development of the person. cases one eye has had it after the other. The upper or lower part of the cornea in the position of a Hutchinson's salmon patch has been occupied by a prominent fleshy mass resembling a neoplasm. The adjoining cornea next the central part of the edge of the mass has shown interstitial deposits or in more advanced cases the rest of the cornea has exhibited the appearances of interstitial keratitis of marked severity. In time the fleshy looking mass becomes flush with the surface of the cornea and is not followed by local bulging.

These cases are perhaps more tedious but run much the same course as the ordinary ones. When both corneae are affected the diagnosis is easy, for bilateral tumors are rare; but in one eye the mass may be taken for papilloma, sarcoma or other form of new growth, and this especially when the mass forms the first sign of disease. Age of patient, normal and adjacent conjunctiva, evidences of syphilis, and the course of the disease will settle the diagnosis. Detailed description of two cases is given.

\section{PARINAUD'S CONJUNCTIVITIS.}

Verhoeff, five years ago, reported finding leptothrices in eleven cases of Parinaud's conjunctivitis and he now adds six more cases in each of which the characteristic leptothrices -were found in large numbers. The author's report is detailed and important so we quote his description and summary in full. "Leptothricosis conjunctivae is a subacute inflammatory condition of the conjunctiva due to infection with a minute leptothrix and is always associated with inflammatory enlargement of the preauricular or other regional lymph glands. The source of the infection is unknown. In some cases there is a history of slight trauma to the conjunctiva preceding the infection. The incubation period is from three to seven days. The conjunctival lesions consist of focal areas situated immediately beneath the epithelium infiltrated with endothelial phagocytes in various stages of necrosis. These appear as opaque greyish areas from $1 / 2 \mathrm{~mm}$. to $4 \mathrm{~mm}$. in diameter, single or multiple, and may appear in any part

PSEUDO-NEOPLASTIC INTERSTITIAL KERATITIS.

Stephenson publishes two cases of this kind of interstitial keratitis which he believes may of the conjunctiva. They contain the leptothrices in great numbers. More or less gran 
ulation tissue is formed causing the conjunctiva to project in the form of polypoid nodules. Uleeration seldom, if ever, occurs. Often the normal conjunctival lymph follicles are greatly enlarged. Congestion and oedema extend through the whole of the lids. Secretion is slight and muco-purulent in character. The cornea is unaffected. Constitutional symptoms are slight or wanting. The affected glands seldom break down. The disease attacks children and young adults; males are affected more frequently than females, and it is usually unilat. eral. It is more prevalent in winter and is not transmitted from one individual to another. The best treatment is excision of the grey areas and nodules.

\section{BLUE SCLEROTICS.}

The relation between blue scleroties and fragilitas ossium was reviewed here several years ago, and now new facts have come to light. In addition to a tendency to fractures, dislocations and sprains these patients have been found to have deafness of the oto-sclerotic type. Bronson reports two families. In one 35 members and four generations were examined. There was a tendency (1) to fractures and dislocations, (2) peculiar shape of the head, (3) blue grey sclerotics, (4) deafness, (5) small stature. Twenty-one individuals had the blue sclerotics. The second family in three generations had eight persons, of whom seven had blue sclerotics and tendency to fractures from slight injury and peculiar shape of the head, but no deafness was found in any of these. Van der Hoeve and de Kleijn in fifteen members, of a family of twenty-two, in four generations found eleven cases of blue sclerotics, every one of whom was deaf and ten of them had broken one or more bones. The patients were small, the deafness oto-sclerotic. The ancestors of this pedigree were not relations. These observers report another family with several members showing all these signs. Conlon reëxamined the cases he reported in 1913 and found that all who had blue scleroties were also deaf and the members of the family with normal sclera had normal hearing.

\section{Soripty Reparts.}

\section{AMERICAN ACADEMY OF POLITICAL AND SOCIAL SCIENCE.}

CONFERENCE ON THE REHABILITATION OF THE WOUNDED, HELD AT WITHERSPOON HALL, PHILADELPHIA, SEPTEMBER 20-21, 1918, DR. WILMER KRUSEN, DIRECTOR OF DEPARTMENT OF PUBLIC HEALTH AND CHARITIES, PHILADELPHia, PRESIDING.

\section{NATURE AND SCOPE OF PROBLEM.}

Dr. W. W. KeEN, Philadelphia: The fundamental difference between the surgical conditions during the Civil War and the present World War is our ignorance in 1861 and the enormous increase in our knowledge since that date. In chemistry and in physies the chief advances in fifty years have been made by experimental research. In biology and its subdivisions of medicine the same is true. The almost virgin fields of battle during the Civil War held few bacteria, hence, while tetanus was not common, it was deadly, killing nine of every ten victims. In the early days of the present World War it exacted a fearful toll of lives, exact figures of which can be given only after the war is over. As soon as there was a sufficient supply of the tetanus antitoxin for the huge numbers of the wounded the ravages of tetanus were checked, and as a result few now die from lockjaw. Every hour of delay, however, in giving the protective serum means a life lost. In the Civil War compound fractures killed two out of every three, amputations averaged over fifty per cent. mortality. Only 25 per cent. of the cases of compound fractures are now fatal instead of 66 per cent., as in the '60's. Our victory over infection is the reason for the greatly diminished number of amputations now done. Moreover, the mortality of amputations at present is low; in some series every one recovered. The present war is waged in densely infected soil, the wounds are caused by high explo. sives and there is developed an unprecedented riot of infection utterly unknown prior to 1914. If the wounded can be brought to the surgeon in the few golden hours, two out of three can be saved. Out of 400 cases in Carrel's hospital in which primary healing could not be secured because of delay in reaching surgical aid, only six were failures. This is due 